\title{
Design of a Low-cost Pulse Oximeter
}

\author{
Xiaoming Gao \\ Department of Computer Science and Technology \\ Southwest University of Science and Technology \\ Mian Yang, China \\ e-mail: $13585018 @$ @q.com
}

\begin{abstract}
Saturation oxygen is an important biological indicator for the respiratory and circulatory of the human being. Many clinical disease can result in insufficient oxygen supply, which will directly affect the normal metabolism of cells, a serious threat to health, so the real-time monitoring of arterial oxygen concentration is very important in the clinical application. This paper introduced to the use of STM8L ultra-low-power microcontroller as the main chip, and using a fingertip photoelectric sensor, in the red wavelength of $660 \mathrm{~nm}$ and $940 \mathrm{~nm}$ infrared light as the probe light source, and use the appropriate signal amplifier, those provides a quick means of direct actions for clinical blood oxygen saturation measured by non-invasive method. The method uses a transmissive principle to monitor the pulse beat and the signal amplitude, and calculates the blood oxygen saturation parameter. The results of experiment show that the system as a whole is low-power consumption, stable performance, accurate measurement.
\end{abstract}

Keywords- Oximeter; Pulsation; STM8L; Transmissive

\section{INTRODUCTION}

Saturation oxygen (SO2) concentration of oxygen in the blood, i.e. the blood to be oxygenated hemoglobin oxygen binding $(\mathrm{HbO} 2)$ can be combined with the total capacity of the percentage of hemoglobin $(\mathrm{Hb})$ capacity, which is an important physiologic respiratory cycle parameters. The functional oxygen saturation of $\mathrm{HbO} 2$ concentration and $\mathrm{HbO} 2+\mathrm{Hb}$ concentration ratio is different from the percentage of oxyhemoglobin. Therefore, monitoring of arterial saturation oxygen $(\mathrm{SaO} 2)$ can estimates for lung oxygenation and hemoglobin oxygencarrying capacity . Normal human arterial blood saturation oxygen was $98 \%$, venous blood is $75 \%$.

Pulse Oximeter uses properties absorption of different lengths waves deoxygenated hemoglobin and oxyhemoglobin, to measure arterial saturation oxygen. It usually consists of the sensors and data acquisition system, those on a patient ear lobe, toes, fingers or other body parts, which can be used to calculate the degree of oxygen saturation, heart rate and blood flow.

The system calculates both the concentration and oxygen saturation of hemoglobin by measuring the intensity of the light conducting portion. The system uses ST's ultra-low-power STM8L-based microcontrollers as the main chip, using a fingertip photoelectric sensor, in the red wavelength of $660 \mathrm{~nm}$ and $940 \mathrm{~nm}$ infrared light as the probe light source, and use the appropriate signal amplifier.

\section{THE PRINCIPLE OF MEASUREMENT}

Hemoglobin from human blood oxygenated hemoglobin $(\mathrm{HbO} 2)$ and reduced hemoglobin $(\mathrm{Hb})$ composition, oxygen saturation level is defined as the ratio

\author{
Xia You \\ Department of Computer Science and Technology \\ Southwest University of Science and Technology \\ Mian Yang, China \\ e-mail:youzi_forever@aliyun.com
}

of oxygenated hemoglobin and total hemoglobin levels are as follows:

$$
\mathrm{SaO}_{2}=\frac{\mathrm{HbO}_{2}}{\mathrm{HbO}_{2}+\mathrm{Hb}} \times 100 \%
$$

Because of oxygenated hemoglobin ( $\mathrm{HbO} 2)$ and reduced hemoglobin $(\mathrm{Hb})$ on the frequency of visible light and near-infrared frequencies of light with different absorption characteristics: of oxygenated hemoglobin $(\mathrm{HbO} 2)$ capable of absorbing a large amount of infrared light frequencies, absorbs less red light, and reduced hemoglobin $(\mathrm{Hb})$ on the contrary, the use of this distinction can be calculated oxygen saturation $\mathrm{SaO} 2$.

Based on Lambert-Beer's law, the amount of light absorbed is proportional to the number of molecules of the optical path of the light absorption is generated, with the following formula (2):

$$
A=\lg \left(\frac{I_{0}}{I}\right)=k c d
$$

In which : $A$ represents the absorbance, $\frac{I_{0}}{I}$ represents the ratio of the light intensity and the transmitted intensity of the incident light, $I$ represents transmitted light intensity, $\boldsymbol{I}_{\mathrm{o}}$ represents the intensity of incident light, $d$ denotes a light transmission path in the body tissues, $k$ is a light absorption coefficient in the blood, $c$ represents molar concentration of light-absorbing substance. System design is the use of the parameters to calculate oxygen saturation, as formula (3):

$$
\mathrm{SaO}_{2}=\frac{c_{\mathrm{hbo}_{2}}}{c_{h b o_{2}}+c_{h b}} \times 100 \%
$$

When the probe light through the stationary tissue and arterial blood, the intensity of the light transmitted by the formula (4):

$$
I_{d c}=I_{0} \rho \times e^{-k_{h b o_{2}} c_{h b o_{2}} d_{h b o_{2}}} \times e^{-k_{h b_{2}} c_{h b_{2}} d_{h b 2}}
$$

In which: $\rho$ represents the total absorption parameter and independent of the pulsation. When arterial pulse, the light transmission path changes $\Delta d, I$ is defined as the amount of change in light transmission intensity, then

$$
\begin{gathered}
\frac{\boldsymbol{I}_{a c}}{\boldsymbol{I}_{d c}}=R \times \Delta d \\
\boldsymbol{R}=-\left(\boldsymbol{k}_{h b o_{2}} c_{h b o_{2}}+k_{h b} c_{h b}\right)
\end{gathered}
$$

Since $\Delta d$ belongs to an unknown parameter, the use of two or more beams of different frequencies of light as 
the detection light, can be easily offset $\Delta d$ As in formula (7):

$$
\frac{I_{a c}^{\lambda 1}}{I^{\lambda 1}{ }_{d c}} / \frac{I_{a c}^{\lambda 2}}{I^{\lambda 2}{ }_{d c}}=R^{\lambda 1} / R^{\lambda 2}
$$

Into the oxygen concentration in the formula to get the formula (8):

$$
\mathrm{SaO}_{2}=k_{h b}^{\lambda 1} /\left(k_{h b}^{\lambda 1}-k_{h b o_{2}}^{\lambda 1}\right)-k_{h b}^{\lambda 2} /\left(k_{h b}^{\lambda 2}-k_{h b o_{2}}^{\lambda 2}\right) \times \frac{I^{\lambda 1}{ }_{a c} I^{\lambda 2}{ }_{d c}}{I^{\lambda 1}{ }_{d c} I^{22}{ }_{a c}}
$$

The above formula is a constant for the same frequency of light, $\mathrm{k}$, which can be determined by the calibration value, and the light intensity of the body tissue can be transmissive using the light-sensitive device to determine the magnitude of the electrical signal.

\section{DESIGN OF SYSTEM SCHEME}

Hardware system of Pulse Oximeter consists of a fingertip photoelectric sensor, LED driver circuit, signal reception and sampling circuit, microcontroller systems and display devices constituted. A data communication interface can be increased on the system, such as USB interface, a Bluetooth interface, etc., to facilitate the detection of data to upload, to extend the functionality of the system. System structure shown in Fig .1:

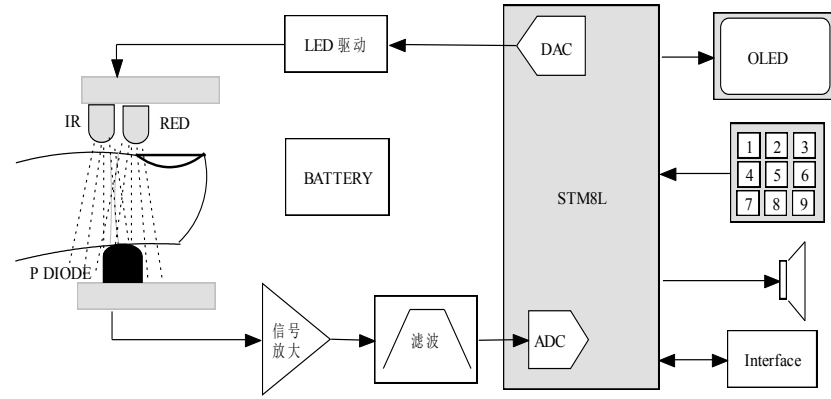

Figure 1. Block diagram of the system.

The microcontroller uses ST's ultra-low-power STM8L family of microcontrollers STM8L152C8. The MCU is an ultra-low-power microcontroller, using a new ultra-low leakage process and optimized architecture, a collection of high performance and low power consumption in one, with four kinds of ultra-low-power operating modes. It can meet the application within $6 \mu \mathrm{A}$ require continuous monitoring, and meet the low power requirements of a variety of special applications, in particular the application of portable medical devices.

\section{DESIGN OF CIRCUIT AND PROGRAM}

\section{A. LED driver circuit}

The system uses two or more beams of light of different frequencies as the probe light, so the system uses a two H-bridge to drive the LED work alternately. One produces invisible infrared light, a wavelength of $660 \mathrm{~nm}$; another to produce infrared light, a wavelength of $940 \mathrm{~nm}$. Drive circuit diagram shown in Fig .2:

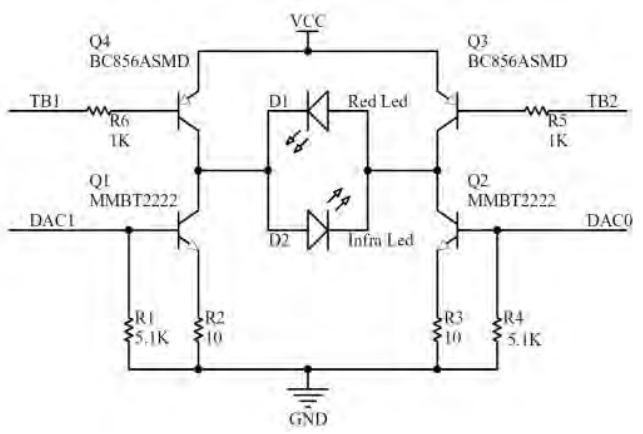

Figure 2. Diagram of driver circuit.

TB1 and TB2 connect the microcontroller STM8L152C8 universal port for driving the complementary circuits. DAC0 and DAC1 connected to the STM8L152C8's DAC0 output port for controlling the current through the LED to thereby control the output intensity of the signal. STM8L152C8 interior comes in two 12bit DAC, which greatly simplifies the system design and software design.

\section{B. Signal receiving and sampling circuit}

The photodiode generates a current signal from the received to the red or infrared rays. This signal which contains a large DC component and relatively small the AC component. The signal is amplified, filtered, then it fed into microcontroller operations by the A/D samples. Signal receiving circuit shown in Fig .3:

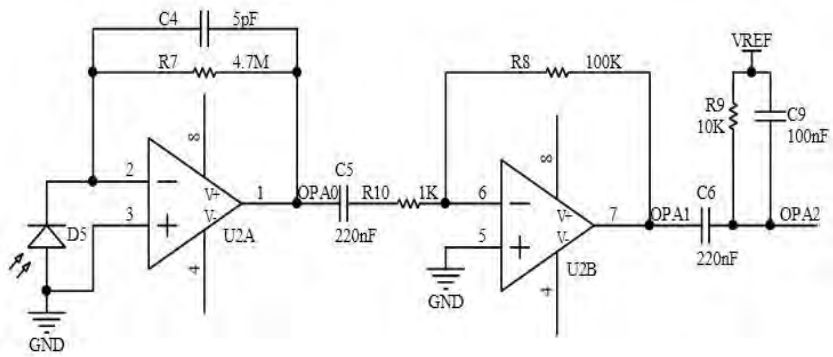

Figure 3. Signal receiving circuit.

Photodiode current signal generated by a transimpedance amplifier for signal amplification. The amplified signal OPA0 contains approximately $1000 \mathrm{mV}$ DC part and 10mVPP AC portion. After filtering DC component by capacitor $\mathrm{C} 5$, through the back-end amplifier signal amplification to $\pm 1000 \mathrm{mVPP}$, then adjust the reference voltage VREF, the control signal amplitude between VREF $+1000 \mathrm{mV}$ and VREF- $1000 \mathrm{mV}$, finally signal sampled by STM8L152C8 comes with ADC.

\section{Microcontroller system circuit}

The system uses ST's ultra-low-power STM8L family of microcontrollers STM8L152C8. The chip comes with two 12bit DAC output to control two LED drive current, while the chip also has up to 2812 bit DAC input port, optical detection signal acquisition and battery power of detection. The part of the circuit system microcontroller shown in Fig .4: 


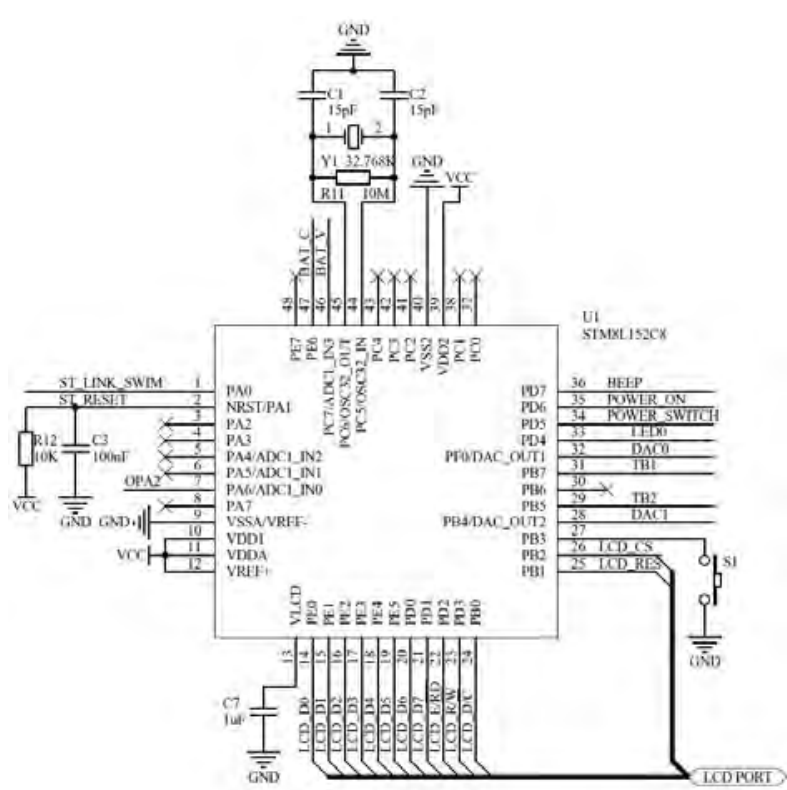

Figure 4. Microcontroller system circuit

Because the micro-controller chip comes with a $16 \mathrm{MHZ}$ RC oscillator, So, omitted the external system clock. To further reduce the power consumption of the system is equipped with an external quartz crystal $32.768 \mathrm{KHZ}$ for internal real-time clock. The system's other $\mathrm{I} / \mathrm{O}$ port is also used for key input, OLED display, power control, etc.

\section{System peripheral circuits}

System peripheral circuits includes buttons, buzzer, LED indicator, power detection, power control, OELD display, etc., to work together to implement the entire system.

The module of system displays uses a panel size of 0.96 inches, the display resolution of $128 \times 64$ OLED display. The display's interface is simple, microcontroller port can drive, display high brightness, low power consumption, but also has the characteristics of selfluminous, with a lot of LCD incomparable advantages, widely used in micro-instrumentation.

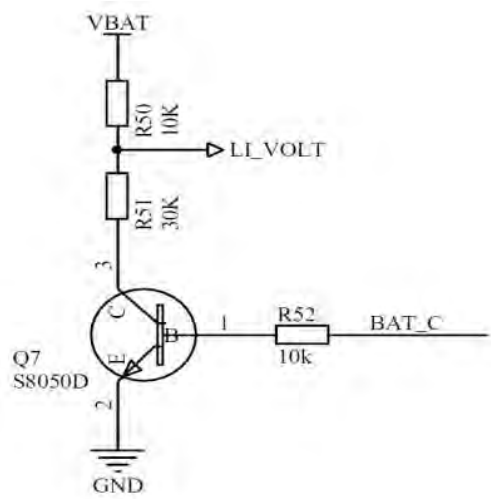

Figure 5. Battery check circuit.

System utilizes an ADC port to monitor the battery power as shown above in Fig .5. Through a port of the microcontroller controls Q7 is turned on, the use of R50 and R51 for dividing a voltage of the battery, and the voltage signal divided fed into LI_VOLT ADC port. Only in the case of the method Q7 will have conduction power loss, and thus will not cause a waste of battery power.

System power switch also utilizes two ports microcontroller control, as shown in Fig .6. By default, the pull of R16 so Q6 is off. When S2 is pressed, Q6 is turned on, the system main power is turned on, the electrical work on the microcontroller and use $\mathrm{I} / \mathrm{O}$ port pulled high POWER SWITCH, at this time you can release the S2 button. When $\mathrm{S} 2$ is pressed again, POWER ON pin detects the button is pressed, the microcontroller turn off the power program, will POWER SWITCH port down, power from the system shutdown. The circuit structure is simple, low cost, and almost does not consume battery power at the system is shutdown state.

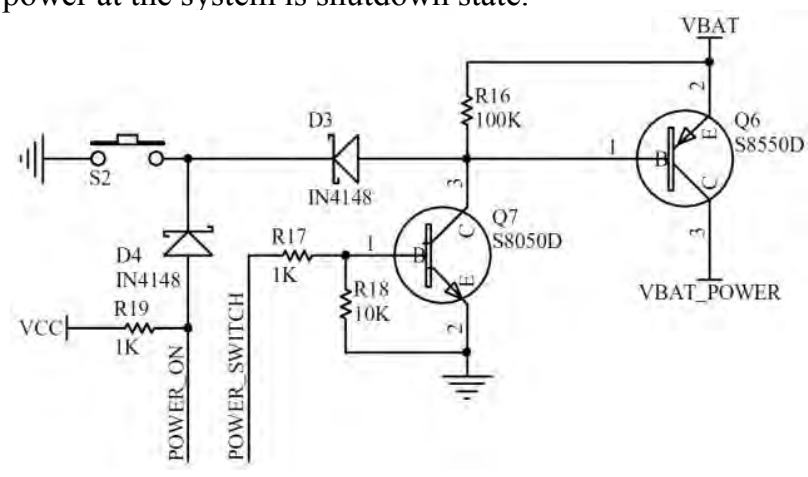

Figure 6. Power switching circuit.

\section{E. System workflow}

In practical applications, the use of a fingertip photoelectric sensor detection. By infrared and red light emitting diode diodes work alternately, with each pulse and the detection intensity of the two beams of light received by the beating of the signal peak, and to the correction signal. While taking advantage of the appropriate algorithm to calculate the frequency of the pulse beat, blood oxygen saturation. And pulse rate curve and the display results are plotted on the screen. Workflow shown in Fig .7: 


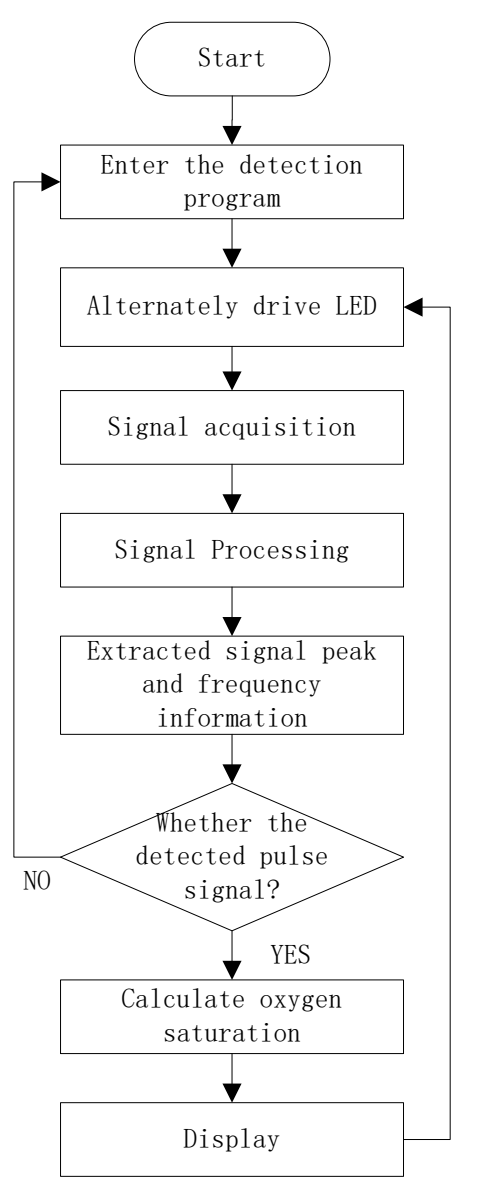

Figure 7. Process of oxygen saturation detection.

\section{RESULTS OF EXPERIMENT}

\section{A. Test objectives, methods and instruments}

Designed and produced a mini-finger Formula oximetry instrument, while pulse rate measurements can be achieved according to the method described above. Detailed in Table 1:

TABLE I. TEST OBJECTIVES AND METHODS AND INSTRUMENTS

\begin{tabular}{|l|l|l|l|}
\hline \multicolumn{1}{|c|}{ Test target } & \multicolumn{1}{|c|}{$\begin{array}{c}\text { Test } \\
\text { instrument }\end{array}$} & \multicolumn{1}{|c|}{$\begin{array}{c}\text { Instrument } \\
\text { model }\end{array}$} & Test method \\
\hline $\begin{array}{l}\text { Functional } \\
\text { Test }\end{array}$ & - & - & $\begin{array}{l}\text { System } \\
\text { functions }\end{array}$ \\
\hline Power Test & $\begin{array}{l}\text { Microampere } \\
\text { meter }\end{array}$ & GDM-8261 & W=UI \\
\hline $\begin{array}{l}\text { Oxygen } \\
\text { Saturation }\end{array}$ & $\begin{array}{l}\text { Standard } \\
\text { equipment }\end{array}$ & CMS-50D & $\begin{array}{l}\text { Error } \\
\text { comparison }\end{array}$ \\
\hline $\begin{array}{l}\text { Pulse } \\
\text { Frequency }\end{array}$ & $\begin{array}{l}\text { Standard } \\
\text { equipment }\end{array}$ & CMS-50D & $\begin{array}{l}\text { Error } \\
\text { comparison }\end{array}$ \\
\hline
\end{tabular}

Through the test, the overall system is functioning properly, including normal startup, shutdown, low battery detection, alarm and so on. At the same time the system can achieve Oxygen Saturation Measurement and pulse rate measurements, low power consumption, the measurement results are shown in Table 2:
TABLE II. RESULTS OF TEST

\begin{tabular}{|c|c|c|c|c|c|}
\hline $\begin{array}{c}\text { Sam } \\
\text { ples }\end{array}$ & $\begin{array}{c}\text { Oxygen } \\
\text { saturati } \\
\text { on } \\
\text { error } \\
\text { (averag } \\
\text { e) }\end{array}$ & $\begin{array}{c}\text { Pulse } \\
\text { frequen } \\
\text { cy error } \\
\text { (averag } \\
\text { e) }\end{array}$ & $\begin{array}{c}\text { Work } \\
\text { ing } \\
\text { curre } \\
\text { nt }\end{array}$ & $\begin{array}{c}\text { Standb } \\
\mathbf{y} \\
\text { Current }\end{array}$ & $\begin{array}{c}\text { Shutdo } \\
\text { wn } \\
\text { Current }\end{array}$ \\
\hline 1 & $\pm 0.4 \%$ & $\pm 2 / \mathrm{min}$ & $32 \mu \mathrm{A}$ & $9 \mu \mathrm{A}$ & $\begin{array}{c}\text { Unable } \\
\text { to detect }\end{array}$ \\
\hline 2 & $\pm 0.6 \%$ & $\pm 1 / \mathrm{min}$ & $32 \mu \mathrm{A}$ & $9 \mu \mathrm{A}$ & $\begin{array}{c}\text { Unable } \\
\text { to detect }\end{array}$ \\
\hline 3 & $\pm 0.4 \%$ & $\pm 2 / \mathrm{min}$ & $32 \mu \mathrm{A}$ & $9 \mu \mathrm{A}$ & $\begin{array}{c}\text { Unable } \\
\text { to detect }\end{array}$ \\
\hline 4 & $\pm 0.7 \%$ & $\pm 2 / \mathrm{min}$ & $32 \mu \mathrm{A}$ & $9 \mu \mathrm{A}$ & $\begin{array}{c}\text { Unable } \\
\text { to detect }\end{array}$ \\
\hline
\end{tabular}

\section{B. Analysis of test results}

Used in the above test 4 different test samples for 10 consecutive times for each sample tested. The test results and compare a wide range of applications currently available oximeter compare products, small error. The results show that the system power consumption is relatively low, fully able to meet the long-term work in the case of battery-powered devices, normal measurement standard oxygen saturation range, with a low standard error of measurement results oximeter, blood oxygen to meet the body saturation measurement needs.

\section{CONCLUSIONS}

Oxygen saturation and pulse rate is an important parameter of the human body medicine. This paper introduces design principles and methods of a complete blood oxygen saturation measurement instrument by using ST's STM8L family of microcontrollers with ultra-low power consumption STM8L152C8. System circuit structure is simple, compact, low power consumption, to achieve a more comprehensive functional oxygen saturation measurement instrument prototype. Experimental results show that the system measurement results and reliable performance. It can meet the needs of home users daily care, and it have greater market prospect.

\section{REFERENCES}

[1] Xu Kexin, Gao Feng, Zhao Huijuan. Biomedical Photonics (second edition) [M]. Science Press.

[2] Liu Shuying, Cai Shengyue, Wang Wenhui. Circuits and Electronics (second edition) [M]. Electronic Industry Press.

[3] Ren Xiao-xi, Liu Qing. Study of dynamically reconfigurable algorithm for low-power cache[J]. Application Research of Computers, 2013,30(2):414-416.

[4] Li Jinjing, Yu Haixun, Cai Xuejun. Design of Pulse Oxygen Center Measurement and Monitoring System Based On WSNs[J]. Computer Measurement \& Control, 2009, 17(6):1135-1140.

[5] Wu Huaichao, Zhou Yong. Development of Virtual Instruments and MSP430 microcontroller-based data acquisition system[J]. Control and Instruments in Chemical Industry, 2011, 38(1): 52-55.

[6] Zhen Guoyong, Pei Junjie. Aanalysis of Analog acquisition accuracy factor analysis[J]. Control and Instruments in Chemical Industry, 2010, 37(12): 117-119.

[7] Zhang Hong, Jin Jie, Sun Weixin. The Development of a Digital Pulse Oximetry System[J]. BME \& Clin Med, 2002, 6 (3):125-128.

[8] Wen Hua, Zhang Yajun. Research of Low Power Consumption Design in Embedded System[J]. Modern Electronics Technique, $2009,32(22): 20-25$ 
[9] Gong Yushun, Wu Baoming, Gao Dandan, et al. Design of an Anti-Noise Wearable Pulse Oximetry[J]. Chinese Journal of Sensors and Actuators, 2012, 25(1):6-10

[10] Wang Lingao, Zhu Qian. On the Wireless Synchronous Acquisition System of Oxygen Content of Brain and Muscles and Hear Rate in Physical Exercise[J]. Chinese Journal of Sensors and Actuators, 2008, 21(12) : 1981-1985.
[11] Jin Hailong, Wang Zuojun, Zhen chengbo, et al. Wireless transmission pulse oximetry noninvasive monitoring application $[\mathrm{J}]$. Chinese Journal of Sensors and Actuators, 2006, 25(1) : 76-78.

[12] Shen Dehai, Liu Dacheng, Xing Tao. Adaptive-selection filtering strategy algorithm on noise density detection[J]. Application Research of Computers, 2012, 29(2) : 761-763. 